\title{
A Biocompatible Synthetic Lung Fluid Based on Human Respiratory Tract Lining Fluid Composition
}

\author{
Abhinav Kumar' • Wachirun Terakosolphan' • Mireille Hassoun' • Kalliopi-Kelli Vandera' • \\ Astrid Novicky' ${ }^{\prime}$ Richard Harvey',2 ${ }^{\text {}}$ Paul G. Royall' • Elif Melis Bicer ${ }^{3} \cdot$ Jonny Eriksson ${ }^{4}$. \\ Katarina Edwards ${ }^{4}$. Dirk Valkenborg ${ }^{5,6,7} \cdot$ Inge Nelissen ${ }^{5}$. Dave Hassall ${ }^{8} \cdot$ lan S. Mudway ${ }^{3}$. \\ Ben Forbes'
}

Received: 7 February 2017 / Accepted: 27 April 2017 / Published online: 30 May 2017

(C) The Author(s) 2017. This article is an open access publication

\begin{abstract}
Purpose To characterise a biorelevant simulated lung fluid (SLF) based on the composition of human respiratory tract lining fluid. SLF was compared to other media which have been utilized as lung fluid simulants in terms of fluid structure, biocompatibility and performance in inhalation biopharmaceutical assays.

Methods The structure of SLF was investigated using cryotransmission electron microscopy, photon correlation spectroscopy and Langmuir isotherms. Biocompatibility with A549 alveolar epithelial cells was determined by MTT assay, morphometric observations and transcriptomic analysis. Biopharmaceutical applicability was evaluated by measuring the solubility and dissolution of beclomethasone dipropionate (BDP) and fluticasone propionate (FP), in SLF.
\end{abstract}

Abhinav Kumar and Wachirun Terakosolphan contributed equally to this work.

Ben Forbes

ben.forbes@kcl.ac.uk

Institute of Pharmaceutical Science, Faculty of Life Sciences and Medicine King's College London, London SEI 9NH, UK

2 Institute of Pharmacy, Martin-Luther-Universität Halle-Wittenberg, 06108 Halle (Saale), Germany

3 MRC-PHE Centre for Environment and Health and NIHR-HPRU in Health Impact of Environmental Hazards, Environmental and Analytical Research Division, Faculty of Life Sciences and Medicine King's College London, London SEI 9NH, UK

4 Department of Chemistry - BMC, Uppsala University, Uppsala, Sweden

5 Health Unit, VITO NV, 2400 Mol, Belgium

6 Interuniversity Institute for Biostatistics and statistical Bioinformatics Hasselt University, 3500 Hasselt, Belgium

7 Centre for Proteomics, University of Antwerp, 2000 Antwerp, Belgium

8 GSK Medicines Research Centre, Gunnels Wood Road, Stevenage Hertfordshire SGI 2NY, UK
Results SLF exhibited a colloidal structure, possessing vesicles similar in nature to those found in lung fluid extracts. No adverse effect on A549 cells was apparent after exposure to the SLF for $24 \mathrm{~h}$, although some metabolic changes were identified consistent with the change of culture medium to a more lung-like composition. The solubility and dissolution of BDP and FP in SLF were enhanced compared to Gamble's solution.

Conclusion The SLF reported herein constitutes a biorelevant synthetic simulant which is suitable to study biopharmaceutical properties of inhalation medicines such as those being proposed for an inhaled biopharmaceutics classification system.

KEY WORDS aerosol beclomethasone dipropionate . biopharmaceutics - dissolution - fluticasone propionate . inhalation · solubility

\section{ABBREVIATIONS}

BDP Beclomethasone dipropionate

CCM Gell culture medium

DPPC 1,2-dipalmitoyl-sn-glycero-3-phosphocholine

DPPG 1,2-dipalmitoyl-sn-glycerol-3-phosphot-rac(1-glycerol)

FDR False discovery rate

FP Fluticasone propionate

GO Gene ontology

HBBS Hank's balanced salt solution

KEGG Kyoto Encyclopedia of Genes and Genomes

MTT 3-(4,5-dimethylthiazol-2-yl)-2,5-diphenyltetrazolium bromide

pAcc The total perturbation accumulation

PORA The over-representation

pMDI Pressurised metered dose inhaler

RTLF Respiratory tract lining fluid

SDS Sodium dodecyl sulfate

SLF Simulant lung lining fluid

TEM Transmission electron microscopy 


\section{INTRODUCTION}

Drug solubility in lung fluid is an important determinant of the fate of inhaled aerosol medicines. Persistence in the form of a solid particle slows drug availability for target engagement, systemic absorption or metabolism [1-4]. Particles that dissolve slowly provide a sustained release mechanism, but are also susceptible to mucociliary clearance [5] and uptake by macrophages [6], or may lead to drug accumulation [7] or toxicity [8]. These factors, together with recent interest in developing a biopharmaceutical classification system for inhaled medicines [9], have focused attention on drug solubility in the lungs and the need to measure solubility in a medium that is representative of human respiratory tract lining fluid (RTLF). In contrast to intestinal fluid in which drug solubility and dissolution has been investigated extensively [10], the development of lung fluid simulants is in its infancy. Human intestinal fluids have been characterised thoroughly in terms of their composition and structure [11-13]. Simulants have been designed to represent fed and fasted conditions [13,14], studied for their biocompatibility [15] and made available as commercial products [16].

When drug solubility or dissolution in the lungs has been studied, the fluid used to represent RTLF has been water or physiological salt solutions [17] (archetypically Gamble's solution), often supplemented with phospholipids [18-20] or a surfactant such as sodium dodecyl sulphate (SDS) [21,22]. Alternatively, products based on lung surfactant extracts such as Survanta ${ }^{\circledR}$ or Curosurf $\AA$ have been used [23]. The tendency to refer to all these fluids as 'simulated lung fluid' reflects a confusion regarding how best to simulate RTLF in vitro. Emerging data regarding the composition of healthy human lung lining fluid in different regions of the lungs [24] provides an opportunity to design a synthetic lung fluid that incorporates the major or critical components of the fluid that lines the human lungs. For maximum utility, such a simulant should be biocompatible with respiratory cells so that it can be used in models to study lung-particle interactions in vitro.

The aim of this study was to characterize a synthetic simulated lung fluid (SLF) that has been developed based on the composition of human RTLF [25]. SLF was manufactured and compared to other fluids which have been used as simulants for RTLF in terms of structure and biocompatibility with A549 alveolar epithelial cells and inhaled drug solubility and dissolution.

\section{MATERIAL AND METHODS}

\section{Materials}

The $25 \mathrm{mg} / \mathrm{mL}$ stock solutions of 1,2-dipalmitoyl-snglycero-3-phosphocholine (DPPG) and 1,2-dipalmitoyl- sn-glycerol-3-phosphot-rac(1-glycerol) ammonium salt (DPPG) were obtained from Avanti Polar Lipids, Inc. (Alabama, USA). Reagent-grade purified human immunoglobulin ( $\operatorname{IgG})$, lyophilized human albumin, Bioreagent-grade transferrin, Sigma-grade cholesterol, ascorbate, urate, certified reference material-grade glutathione and Hank's Balanced Salt Solution (HBSS) were supplied by Sigma-Aldrich Company Limited (Dorset, UK). HPLC-grade chloroform and water were supplied by Fischer Chemicals (Loughborough, UK). 6 $\alpha, 9$-Difluoro-17-[[(fluoromethyl)sulfanyl] carbonyl]-11 $\beta$ hydroxy-16 $\alpha$-methyl-3-oxo androsta-1,4-dien-17 $\alpha$-yl propanoate (fluticasone propionate: FP) was purchased from Adooq Bioscience (Irwin, CA), 9-Chloro-11 $\beta$-hydroxy-16 $\beta$-methyl-3,20-dioxopregna-1,4-diene-17,21-diyl dipropanoate (beclomethasone dipropionate; BDP) was purchased from Medchem Express (US), and Survanta ${ }^{\circledR}$ from AbbVie Ltd. (UK).

\section{Preparation of Simulated Lung Fluid (SLF)}

The SLF was formulated to contain the most abundant components of healthy human alveolar RTLF in the concentrations that they manifest in vivo as determined recently by Bicer [24] and was prepared as described previously [25] (Table I). Briefly, to prepare the liposomal content, $1.92 \mathrm{~mL}$ DPPG and $0.2 \mathrm{~mL}$ DPPG, from $25 \mathrm{mg} / \mathrm{mL}$ stock solutions in chloroform were combined and $5 \mu \mathrm{L}$ of cholesterol from a $200 \mathrm{mg} / \mathrm{mL}$ stock solution in chloroform was added. The mixture was stirred gently in a round bottom flask and the chloroform evaporated under streamed nitrogen gas, to produce a thin layer of lipids at the base of the flask. The proteins were added into the lipid flask in aliquots of aqueous stock solutions: $4 \mathrm{~mL}$ of albumin $(88 \mathrm{mg} / \mathrm{mL}), 4 \mathrm{~mL}$ of IgG $(26 \mathrm{mg} / \mathrm{mL})$ and $1 \mathrm{~mL}$ of transferrin $(15 \mathrm{mg} / \mathrm{mL})$. In order to represent lung antioxidant levels $88.5 \mu \mathrm{L}$ of the following antioxidant stock solutions were added: $10 \mathrm{mM}$ ascorbate, $10 \mathrm{mM}$ glutathione, and $5 \mathrm{mM}$ urate in the HPLG-grade water. The mixture was vortexed

Table I The Composition of Survanta and Simulated Lung Fluid (SLF)

\begin{tabular}{ll}
\hline Survanta ${ }^{\circledR}$ & SLF \\
\hline - Phospholipids $25 \mathrm{mg} / \mathrm{mL}$ & - DPPC $4.8 \mathrm{mg} / \mathrm{mL}$ \\
(including I I.0- $15.5 \mathrm{mg} / \mathrm{mL}$ & - DPPG $0.5 \mathrm{mg} / \mathrm{mL}$ \\
$\quad$ disaturated phosphatidylcholine) & - Cholesterol $0.1 \mathrm{mg} / \mathrm{mL}$ \\
- Triglycerides $0.5-1.75 \mathrm{mg} / \mathrm{mL}$ & - Albumin $8.8 \mathrm{mg} / \mathrm{mL}$ \\
- Free fatty acids $1.4-3.5 \mathrm{mg} / \mathrm{mL}$ & - IgG $2.6 \mathrm{mg} / \mathrm{mL}$ \\
- Protein less than $1.0 \mathrm{mg} / \mathrm{mL}$ & - Transferrin $1.5 \mathrm{mg} / \mathrm{mL}$ \\
& - Ascorbate $\mid 40 \mu \mathrm{M}$ \\
& - Urate $95 \mu \mathrm{M}$ \\
& - Glutathione $\mid 70 \mu \mathrm{M}$ \\
\hline
\end{tabular}


for 5 min, then gently mixed using a vibrating probe for $10 \mathrm{~min}$ at an amplitude of 10 to dissolve the lipids into the solution. Finally, $10 \mu \mathrm{L}$ of gentamicin was added, followed by $775 \mu \mathrm{L}$ of HBSS under gentle mixing.

\section{Characterisation of the SLF}

Cryo-transmission electron microscopy (cryo-TEM) of SLF and Survanta was performed using a Zeiss Libra 120 Transmission Electron Microscope (Carl Zeiss NTS, Oberkochen, Germany). The microscope operated at $80 \mathrm{kV}$ in zero loss bright-field mode under cryo conditions. Digital images were recorded under low dose conditions, with a slow-scan CGD camera (TRS GmbH, Moorenweis, Germany) and iTEM software (Olympus Soft Imaging System GmbH, Münster, Germany). An under focus of 1-2 $\mu \mathrm{m}$ was used to enhance the image contrast. Thinly spread samples were prepared in a $100 \%$ humidity chamber to avoid dehydration, then quickly vitrified in liquid ethane held at a temperature just above its freezing point $\left(-182^{\circ} \mathrm{C}\right)$. After vitrification, the samples were transferred to the microscope using a Gatan CT3500 cryo-transfer (Gatan, Oxon, UK), to maintain samples below $-165^{\circ} \mathrm{C}$.

Photon correlation spectroscopy (Nanosizer, Malvern Instruments, UK) at a scattered angle of $173^{\circ}$ was used to measure the hydrodynamic diameter of structures in SLF and Survanta. Suspensions ( $1 \mathrm{~mL}$ ) of both fluids were analysed using instrument parameters: refractive index 1.330, temperature $25^{\circ} \mathrm{C}$, dynamic viscosity $0.8882 \times 10^{-3} \mathrm{~Pa}$ s. Zetasizer Software 6.20 was used to analyze the data.

A Langmuir trough (Model 602A; Nima Technologies Ltd., Coventry, UK) was used to make surface pressure-area measurements at $23^{\circ} \mathrm{C}$ using a PS4 surface pressure microbalance $(0-240 \mathrm{mN} / \mathrm{m}$ range, $0.1 \mathrm{mN} / \mathrm{m}$ resolution) fitted with a Wilhelmy plate $(1 \mathrm{~cm}$ width Whatman Grade 1 chromatographic paper, GE Healthcare life sciences, Little Chalfont, UK) and controlled by Nima IU4 computer interface unit software. Suspensions of freeze dried SLF and Survanta, $1 \mathrm{mg} / \mathrm{mL}$, were prepared in chloroform, vortexed for $10 \mathrm{~min}$, then bath sonicated at $37 \mathrm{kHz}$, $25^{\circ} \mathrm{C}$, for $10 \mathrm{~min}$. For each isotherm, the test fluid was deposited dropwise onto a $0.9 \% w / v \mathrm{NaCl}$ subphase surface using a Hamilton syringe and spreads rapidly to cover the available area of the trough until the surface pressure reached $20 \mathrm{mN} / \mathrm{m}$, with the barriers open at their maximum. The solvent was allowed to evaporate for $10 \mathrm{~min}$ before the barriers were compressed at $35 \mathrm{~cm}^{2} / \mathrm{min}$. The mean molecular weights of the surface-active components of $\operatorname{SLF}(38,760.9 \mathrm{~g} / \mathrm{mol})$ and Survanta $(843.5 \mathrm{~g} / \mathrm{mol})$ were calculated from their defined compositions and together with the known masses of the deposited monolayers, were used to determine the mean molecular area for each sample. The isotonic saline subphase was used to simulate the influence of normal lung fluid counter-ions on the behavior of the monolayer components [26].

Individual compressions were used to determine the collapse pressure, which was 50 and $60 \mathrm{mN} / \mathrm{m}$ for SLF and Survanta, respectively. Subsequently, each film was compressed to a surface pressure $5 \mathrm{mN} / \mathrm{m}$ below their collapse pressures and then expanded to reach the initial surface pressure, $20 \mathrm{mN} / \mathrm{m}$. Triplicate experiments of ten isotherm cycles were performed for each simulant without an equilibration period between the expansion and re-compression. Each individual compressionexpansion cycle took 10-25 $\mathrm{min}$ to complete. The degree of hysteresis was determined from differences between the compression and expansion isotherms for each cycle. The surface compressional modulus $(K)$ [27], was calculated using eq. 1:

$\kappa=\frac{\mathrm{I}}{C}=-A \times\left(\frac{d \Pi}{d A}\right)_{T}$

where $C$ is compressibility, $\mathrm{A}$ is the mean area per molecule and $\left(\frac{d I}{d A}\right)_{T}$ is the slope of the isotherm at a defined surface pressure. Compressibility is characterized by high surface elasticity and low interfacial stiffness [28]. $K$ ranges between 12.5 and $50 \mathrm{mN} / \mathrm{m}$ for the liquid expanded phase, $50-100 \mathrm{mN} / \mathrm{m}$ liquid intermediate phase and $100-250 \mathrm{mN} / \mathrm{m}$ for the liquid condensed phase [29], whilst the condensed state has $K$ values $>250 \mathrm{mN} / \mathrm{m}$.

\section{Biocompatibility with the Human A549 Cell Line}

Human alveolar epithelial A549 cells (passage 38-46) were cultured in a humidified atmosphere at $37^{\circ} \mathrm{C}$, $5 \% \mathrm{CO}_{2}$ using a cell culture medium (CGM) composed of RPMI-1640 medium supplemented with $10 \% \mathrm{v} / \mathrm{v}$ fetal bovine serum (FBS), $1 \% \mathrm{v} / \mathrm{v}$ L-glutamine and $0.1 \%$ $v / \mathrm{v}$ gentamicin. For the 3-(4,5-dimethylthiazol-2-yl)-2,5diphenyltetrazolium bromide (MTT) assay A549 cells were seeded in 96-well plates at 30,000 cells $/ \mathrm{cm}^{2}$ using reduced serum (2\% FBS) CCM for $48 \mathrm{~h}$ before exposure to SLF or Survanta for $24 \mathrm{~h}$. After $24 \mathrm{~h}$, cells were washed with PBS and $200 \mu \mathrm{L}$ of fresh CCM containing $50 \mu \mathrm{L}$ of MTT solution $(2.5 \mathrm{mg} / \mathrm{mL}$ in PBS) was added to each well and the plate was incubated for $4 \mathrm{~h}$ in a humidified incubator, after which the solution was discarded. The cells were lysed and formazan crystals formed were solubilised with $100 \mu \mathrm{L}$ of a solution of $10 \%$ SDS in dimethylformamide:water (1:1). Cells were incubated with lysis solution overnight at $37^{\circ} \mathrm{C}$ before the absorbance of solubilised formazan was measured at 
570 nm using a SpectraMax microplate reader (Molecular Devices, UK). SLF was non-toxic to A549 cells and was evaluated further using TEM and transcriptomics.

For TEM, A549 cells on glass coverslips were fixed using $2.5 \%(v / \mathrm{v})$ glutaraldehyde in $0.1 \mathrm{M}$ phosphate buffer for $2 \mathrm{~h}$ at $4^{\circ} \mathrm{C}$. Following fixation the cells were rinsed with $0.1 \mathrm{M}$ phosphate buffer and treated with $1 \%(w / v)$ osmium tetroxide in $0.1 \mathrm{M}$ phosphate buffer (pH 7.3) for $20 \mathrm{~min}$ at $4^{\circ} \mathrm{C}$. The coverslips were washed for $10 \mathrm{~min}$ in phosphate buffer and dehydrated in a graded ethanol dilution series 0 to $100 \%$. Finally, the cells were infiltrated with TAAB epoxy resin for $4 \mathrm{~h}$ at room temperature. To section in the plane of the monolayers, the coverslips were embedded in resin and polymerized for $24 \mathrm{~h}$ at $70^{\circ} \mathrm{C}$. Ultrathin sections $(70-$ $90 \mathrm{~nm}$ ) were prepared using a Reichert-Jung Ultracut E ultramicrotome, mounted on 150 mesh copper grids, contrasted using uranyl acetate and lead citrate, and examined on an FEI Tecnai 12 transmission microscope operated at $120 \mathrm{kV}$. Images were acquired with an AMT $16000 \mathrm{M}$ digital camera. Images $(n \geq 6$ for each sample) were acquired and analysed using ImageJ 1.47 software. Effects on cell health was assessed based on morphometry; cellular, nuclear and mitochondrial area.

For transcriptomic analysis, RNA was isolated from the A549 cells in 6-well plates $\left(30,000\right.$ cells $/ \mathrm{cm}^{2}$ in $2 \mathrm{~mL}$ CCM) after $24 \mathrm{~h}$ exposure to with SLF or CGM (control). The cells were washed 3 times with PBS, then lysed with RLT buffer (Qiagen). Total RNA was isolated using an RNeasy mini kit (Qiagen) following the manufactures guidelines. The RNA concentration was determined using a NanoDrop spectrophotometer (NanoDrop Technologies, ThermoFisher, USA). RNA integrity was analysed using the Agilent 2100 Bioanalyzer (Agilent Technologies). Only samples demonstrating high RNA Integrity Number value $(>9)$ were qualified for microarray analysis.

RNA was amplified and labeled using the one-colour LowInput QuickAmp Labeling Kit (Agilent Technologies). Briefly, $200 \mathrm{ng}$ of total RNA was reverse transcribed into complementary DNA (cDNA) using a T7-promoter primer and MMLV reverse transcriptase. The cDNA was transcribed into complementary RNA (cRNA), during which it was fluorescently labeled by incorporation of cyanine(Cy)3-CTP. After purification using the RNeasy mini kit (Qiagen), cRNA yield and specific activity were determined using a NanoDrop spectrophotometer. Only labeled cRNAs showing a specific activity above 8 pmol dye $/ \mu \mathrm{g}$ RNA were analysed. Labeled cRNA, $1.65 \mu \mathrm{g}$, was competitively hybridized onto Whole Human Genome 4 x $44 \mathrm{~K}$ oligonucleotide arrays (G4112F, Agilent Technologies) for $17 \mathrm{~h}$ in a
Tecan HS 4800 Pro Hybridization Station (Tecan Benelux BVBA, Belgium). The arrays were scanned on an Agilent G2565BA microarray scanner and further processed using Agilent Feature Extraction Software (version 10.7.3.1). Data processing steps used to generate the Agilent one-color output was performed as indicated in the Agilent protocol GE1-107-Sep09. For each feature (spot) on the array, gProcessedSignal (normalized values for Cy3 fluorescence), feature quality and gene information were analysed. Normalization included linear scaling and Quantile normalization; data were filtered with regard to reliability including signal strength (only features with signal values $3 x$ the background standard deviation were considered valid features).

\section{Solubility and Dissolution of Poorly Soluble Inhaled Drugs}

The solubility of fluticasone propionate (FP) and beclomethasone dipropionate (BDP) was measured in Gamble's solution, SLF, Survanta and $0.5 \%$ sodium dodecyl sulphate (SDS) by mixing excess drug powder (approximately $0.5 \mathrm{mg}$ ) with $0.5 \mathrm{~mL}$ of the solvent in a microcentrifuge tube. The sealed tubes were vortex mixed for $5 \mathrm{~min}$ before sonication at $37^{\circ} \mathrm{C}$ for $30 \mathrm{~min}$ before transfer to a shaking water-bath at $37^{\circ} \mathrm{C}$. After $48 \mathrm{~h}$, the drug suspensions were centrifuged at $13000 \mathrm{rpm}$ for $10 \mathrm{~min}$, then the supernatant $(0.2 \mathrm{~mL})$ was centrifuged for a second time before $0.1 \mathrm{~mL}$ of supernatant was diluted 10 times with methanol. This sample was analysed for drug concentration by HPLC.

For dissolution experiments Flixotide ${ }^{\circledR} 50 \mu \mathrm{g}$ pMDI or QVAR® $50 \mu \mathrm{g}$ pMDI were actuated 10 times to deliver aerosol to the surface of $0.45 \mu \mathrm{m}$ pore polyester membrane Transwell inserts (membrane pre-wetted with dissolution medium) using a twin stage impinge as described previously [30]. The inserts were transferred to wells in 24-well base-plates containing $600 \mu \mathrm{L}$ dissolution medium (Gambles solution, SLF, or water with $0.5 \% \mathrm{SDS})$. At intervals, the insert was moved to a new well containing fresh dissolution medium. The drug transferred to each receiver chamber was measured at the end of the experiment using HPLC as described previously [30]. The test was performed at room temperature, with each result measured in triplicate.

\section{RESULTS AND DISCUSSION}

\section{Characterisation of SLF}

Uni-, bi-, and oligolamellar liposomes were visualised in the SLF and Survanta using CryoTEM (Fig. la and b). 
The vesicles in SLF and Survanta samples had similar appearance despite their different origins and processing; SLF has a defined compositions and is fabricated from defined individual components, whereas Survanta is an enriched surfactant extract from bovine lungs. Both fluids showed irregular electron-dense structures, which may be protein aggregates. Dynamic light scattering also detected structures in the fluids; SLF showed a strong signal for structures with a size of $57 \mathrm{~nm}$ corresponding to the size of liposomes and a weaker signal for $946 \mathrm{~nm}$. Further interpretation was not possible due to background scattering by multi-molecular protein agglomerates, which is a recognized limitation of dynamic light scattering size analysis in media with high protein content [31].
Langmuir isotherms (pressure-area relationships) were explored to determine whether the apparent similarities in structures observed in the lung fluids extended to the physicochemical behavior of monolayers formed on water. The mean molecular area of SLF was greater than that of Survanta (668-800 $\AA^{2}$ and 48-26 $\AA^{2}$, respectively, over the 10 cycles), possibly due to the albumin (which was present in SLF, but not Survanta) affecting DPPG packing. SLF formed a stable monolayer after the first compression-expansion cycle (Fig. 1b). During compression it underwent transitions from a liquid expanded to intermediate phase, followed by a liquid condensed phase. A large hysteresis loop and shift towards lower molecular area was observed between the first and second compression cycle. The isotherms of the
Fig. I (a) CryoTEM.

Microstructures in synthetic lung

fluid (SLF) and Survanta ${ }^{\circledR}$.

Microstructures imaged in the suspension of SLF and Survanta showing the presence of bilamellar and oligolamellar liposomal vesicles. (b) Isotherms. Isotherm cycles and changes in compressibility modulus over 10 consecutive compressions for SLF and Survanta films measured by LangmuirBlodgett trough.

\section{a}

Cryo-TEM

of simulated lung fluid

\section{b}

Langmuir Isotherms
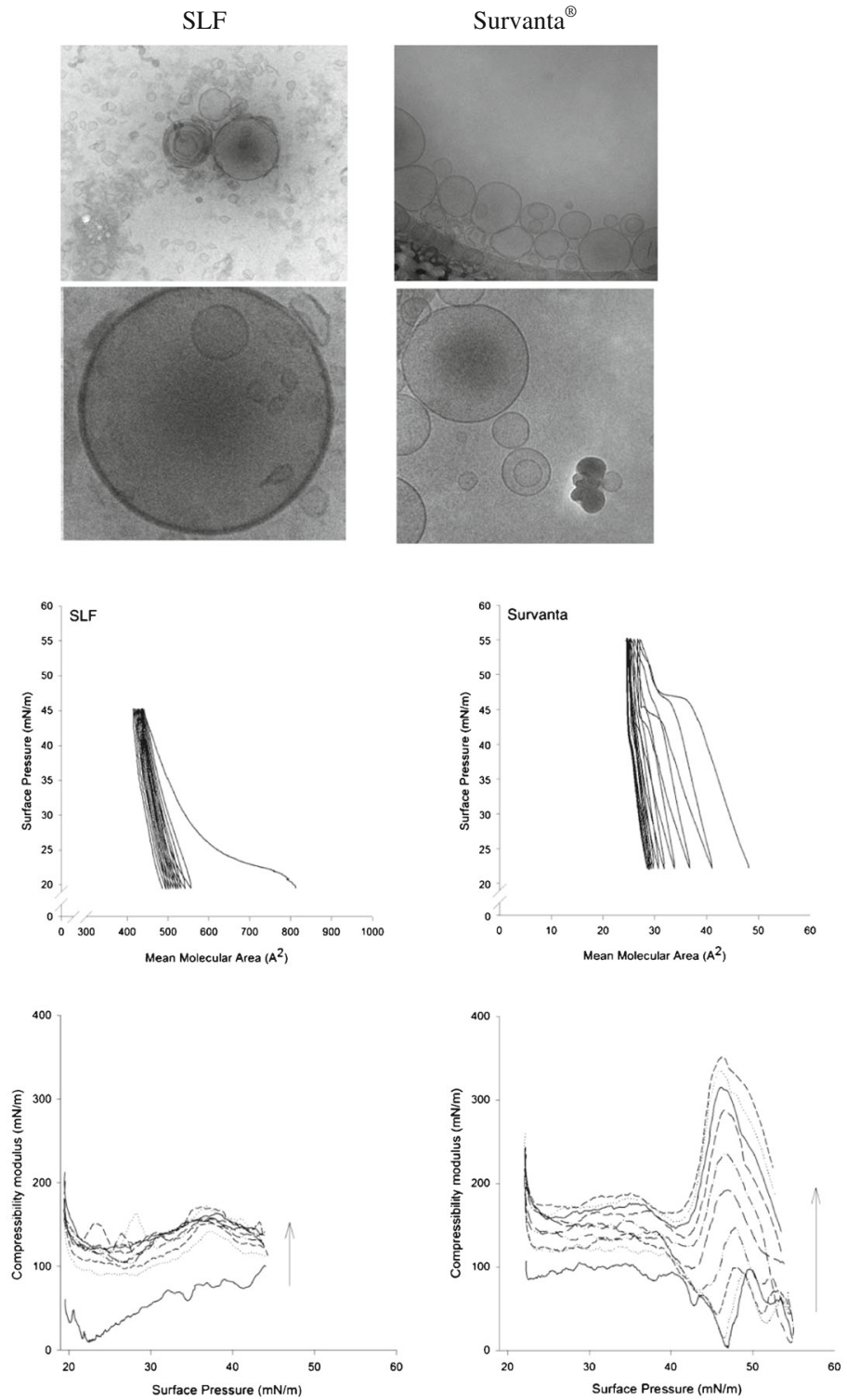
remaining cycles were identical indicating the formation of a stable monolayer.

Three phase transitions were observed in the Survanta isotherm during the first few cycles which disappeared during the later cycles (Fig. 1b). At the initial surface pressure $(20 \mathrm{mN} / \mathrm{m})$ Survanta formed an intermediate phase $(K<100 \mathrm{mN} / \mathrm{m})$, in which liquid expanded and liquid condensed phases are assumed to coexist. Upon compression a plateau phase appeared at around $47 \mathrm{mN} / \mathrm{m}$, which occurred at progressively lower surface pressures over the course of subsequent cycles, followed by an intermediate phase when further compression was applied. Over the course of 10 cycles, hysteresis occurred and the isotherm cycles underwent an inward shift. The systematic shift of hysteresis loops implied that there was an irreversible loss of material from the surface due to the irreversible desorption into the subphase over the course of a compression cycle. The reduced hysteresis after the 7 th cycle indicates the formation of a stable monolayer at this point from which no further loss of material occurred.

The reduction of Survanta compressibility observed over the sequence of compression cycles has been reported previously and attributed to the extrusion of hydrophobic proteins and associated lipids into the subphase [32]. The hydrophobic SP-B and SP-C proteins present in Survanta are thought to facilitate this extrusion, which is normally reversed upon expansion [33]. However, the speed at which the compression/ expansion cycles were repeated may have led to the increasing hysteresis observed in the Survanta isotherms because re-compression began before the monolayer had completed re-spreading. Compared to Survanta, SLF underwent the composition-refining process during the first isotherm cycle when excess material was removed from the interface during the first cycle, indicating a simpler stable colloidal system. These data characterize the structural and mechanical properties of RTLF simulants which may affect drug solubility and dissolution. In vivo, a monolayer depleted in hydrophobic proteins during breathing-cycle related compression will show different wetting characteristics for drug particles settling on its surface compared to the expanded system. Thus the first stages of the particle dissolution process will be affected by compression-dependent monolayer composition, whereas changes in the micellar sub phase will influence bulk solubility. In vitro, the lower stability of the Survanta monolayer indicates a high propensity to form micellar aggregates which are likely to sequester poorly soluble drugs. In contrast, the stability of colloidal structures in SLF make them less likely to sequester drugs in micelles, however its high albumin content will provide a reservoir for poorly-soluble compounds.

\section{Biocompatibility of SLF}

Survanta had a catastrophic effect on A549 cells in the MTT assay, reducing viability by $>90 \%$ after $24 \mathrm{~h}$ exposure. In contrast, SLF and Gamble's solution indicated mitochondrial activity comparable to that observed in HBSS with cellular metabolism remaining within $20 \%$ of that in reduced-serum CCM control (data not shown). The adverse effects of Survanta were mitigated fully by dilution to $21 \%$ Survanta in HBSS (i.e. Survanta diluted to match the phospholipid content of SLF/human RLTF). The apparent biocompatibility of SLF with A549 cells indicated by MTT assay was followed up by exploring any morphometric or transcriptional changes induced by exposure of A549 cells to SLF.

TEM analysis following incubation of SLF with A549 cells revealed no effect compared to control on cellular, nuclear and mitochondrial areas (Fig. 2). Nor were other morphological signs of cell distress observed, e.g. nuclear condensation, crescent shaped condensed chromatin abnormal lamellar bodies or epithelial projections (Fig. 2a). Interestingly, cytoplasmic and membranebound vacuole inclusions (vacuoles at the apical surface of the plasma membrane) were observed, which it is tempting to attribute to uptake of DPPC liposomes following exposure to with SLF (Fig. 2b).

Using microarray analysis, 116 differentially expressed genes $(p<0.05 ; 2$ log-fold change in expression) were identified out of 10,705 genes with measured expression. The data was analysed using iPathwayGuide (Advaita Corporation, 2015) within the context of pathways in the Kyoto Encyclopedia of Genes and Genomes (KEGG) database and gene ontologies (GO) from the Gene Ontology Consortium database. After correction for the false discovery rate, 5 KEGG pathways were found to be affected significantly (Table II). After elim pruning to favour more significant terms, 5 GO terms with a threshold above 10 genes per term were impacted significantly (Table III). The perturbation (pAcc) provides a perturbation factor for each gene and the overrepresentation (pORA) describes the probability of changes to the number of genes affected in a certain pathway (Fig. 3).

Pathway analysis showed that steroid biosynthesis, including biosynthesis of cholesterol, steroid hormones and vitamin $\mathrm{D}$, was significantly induced. This was corroborated by the GO analysis which confirmed induction of the cholesterol, sterol and steroid biosynthetic pathways $(p<0.05)$. This may be the consequence of exogenous cholesterol in SLF. An increase in oxidation-reduction processes may also be related to the increase in cholesterol synthesis, which involves many redox enzymes. As 
a
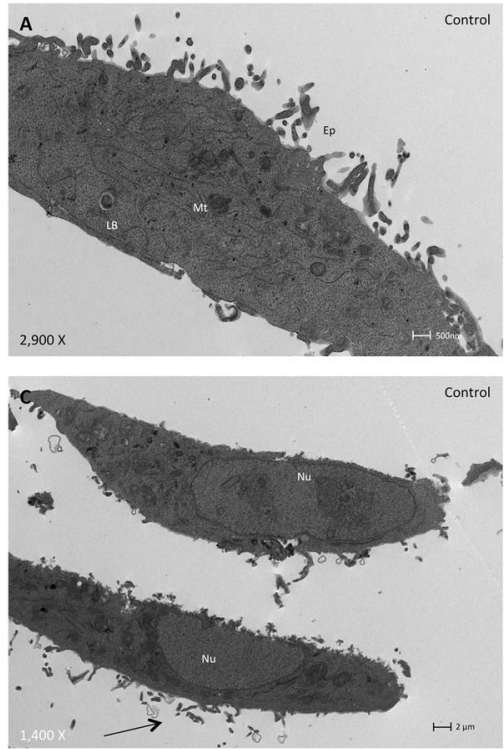

b
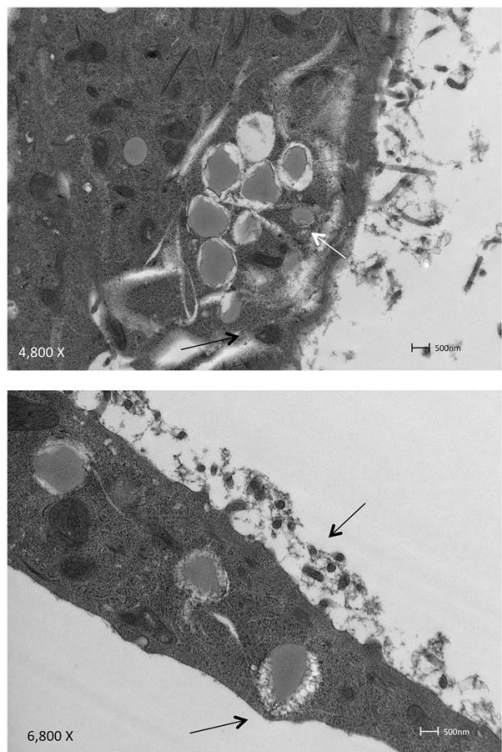

C

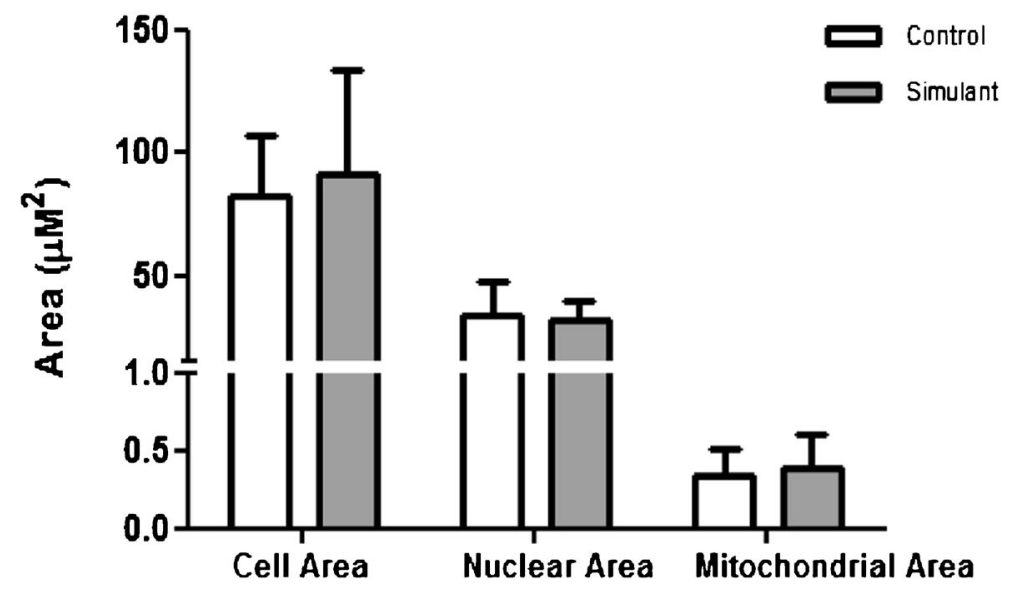

Fig. 2 Morphological characterisation of A549 cells cultured in cell culture medium and SLF for 24 h. (a) Cell morphology. A549 control cells incubated with cell culture medium (left) compared to A549 cell incubated with SLF (right). Scale bar: $2 \mu \mathrm{m}$. (b) Cellular uptake. SLF interaction with A549 cells indicated with arrows. Scale bar: $500 \mathrm{~nm}$ (c) Cell dimensions. Culture medium compared to SLF showing no differences. Data represent mean \pm sd, $n=6$ images. 
Table II The Top (Strongest Signal) Pathways in Rank Order with their p-values: p-values in Bold Represent Significance

\begin{tabular}{lllll}
\hline Pathway name & Pathway id & $p$-value & $p$-value (FDR) & $p$-value (Bonferroni) \\
\hline Steroid biosynthesis & 00100 & $\mathbf{2 . 5 9 9 e - 1 0}$ & $\mathbf{3 . 0 1 5 e - 8}$ & $\mathbf{3 . 0 1 5 e - 8}$ \\
DNA replication & 03030 & $\mathbf{I . 4 9 3 e - 6}$ & $\mathbf{8 . 6 5 8 e - 5}$ & $\mathbf{1 . 7 3 2 e - 4}$ \\
Terpenoid backbone biosynthesis & 00900 & $\mathbf{5 . 5 4 7 e - 5}$ & $\mathbf{0 . 0 0 2}$ & $\mathbf{0 . 0 0 6}$ \\
Metabolic pathways & 01100 & $\mathbf{2 . 8 1 0 e - 4}$ & $\mathbf{0 . 0 0 8}$ & $\mathbf{0 . 0 3 3}$ \\
Tryptophan metabolism & 00380 & $\mathbf{0 . 0 0 2}$ & $\mathbf{0 . 0 3 8}$ & 0.191 \\
Cell cycle & 04110 & $\mathbf{0 . 0 0 2}$ & $\mathbf{0 . 0 4 0}$ & 0.240 \\
\hline
\end{tabular}

many activators of the $\mathrm{NfkB}$ pathway are oxidants, the observed up-regulation in the oxidative-reductive process in this study might indicate that incubation with SLF has immunomodulatory roles [34]. This would be consistent with previous findings demonstrating that DPPC can exert anti-inflammatory effects through the inhibition of the NFkB-pathway [35]. Reduced DNA replication was also identified robustly by pathway and GO analysis, i.e. negative regulation of transcription from RNA polymerase II promotor. This may be explained by the effect of change of culture environment which stalls cell replication in vitro.

Taken together, the MTT, morphometry transcriptomic analyses demonstrate that SLF is biocompatible with A549 cells, though clearly further work will be required to establish how robust this finding is across cell lines and in primary cell models.

\section{Solubility and Dissolution of FP and BDP in SLF}

FP and BDP are poorly water soluble drugs, reported to have concentrations of approximately $0.1-0.2 \mu \mathrm{g} / \mathrm{mL}$ in water [9,36,37]. In Gamble's solution, FP and BDP solubility was 0.7 and $1.0 \mu \mathrm{g} / \mathrm{mL}$, respectively (Fig. 4). In surfactant- containing media, the solubility of FP increased in the rank order: $\operatorname{SLF}(2.0 \mu \mathrm{g} / \mathrm{mL})<0.5 \% \operatorname{SDS}(13.1 \mu \mathrm{g} /$ $\mathrm{mL})<$ Survanta $(20.3 \mu \mathrm{g} / \mathrm{mL})$. The BDP rank order of solubility in the different media was changed, but BDP solubility was higher than that of FP in each medium: SLF $(16.8 \mu \mathrm{g} /$ $\mathrm{mL}),<\operatorname{Survanta}(37.2 \mu \mathrm{g} / \mathrm{mL})$ and $<0.5 \%$ SDS $(64.4 \mu \mathrm{g} /$ $\mathrm{mL}$ ). Lung surfactants enhance the solubility of small, lipophilic drug molecules, such as corticosteroids and cationic compounds because they form structures with lipid domains [38,39]. Unexpectedly, FP solubility in SLF was much closer to that in Gamble's solution than Survanta. Solubilisation may be determined not only by lipid content but also the interaction of components, including the drug, which affect liposomal structures. For example, cholesterol may form tight nanodomain complexes with DPPC stabilising the lamellar structures formed [40], whereas albumin may solubilise the cholesterol [41] and reduce the stability of the lamellar phase and the extent to which drug is solubilised in such structures. A recent review by Das et al. speculates how lung surfactant may form different liquid crystalline phases with potential roles in defining dissolution mechanism and rate [42].

The dissolution of FP and BDP aerosols from licenced inhaler products correlated with drug solubility in the dissolution medium. BDP dissolved more readily

Table III Top Gene Outology (GO) Terms and their p-values: $p$ values in Bold Represent Significance

\begin{tabular}{|c|c|c|c|c|c|c|c|}
\hline \multicolumn{4}{|l|}{ No pruning } & \multicolumn{2}{|l|}{ Elim pruning } & \multicolumn{2}{|l|}{ Weight pruning } \\
\hline GO Term & $p$-value & $\begin{array}{l}p \text {-value } \\
\text { (FDR) }\end{array}$ & $\begin{array}{l}p \text {-value } \\
\quad \text { (Bonferroni) }\end{array}$ & GO Term & $p$-value & GO Term & $p$-value \\
\hline $\begin{array}{l}\text { Sterol biosynthesis } \\
\text { process }\end{array}$ & $2.000 \mathrm{e}-14$ & $5.018 \mathrm{e}-||$ & $5.018 \mathrm{e}-1 \mid$ & $\begin{array}{l}\text { Cholesterol } \\
\text { biosynthesis process }\end{array}$ & $1.900 \mathrm{e}-9$ & Sterol biosynthesis process & $2.000 \mathrm{e}-14$ \\
\hline $\begin{array}{l}\text { Cholesterol } \\
\text { biosynthesis } \\
\text { process }\end{array}$ & $2.300 \mathrm{e}-13$ & $1.924 \mathrm{e}-10$ & $5.771 \mathrm{e}-10$ & $\begin{array}{l}\text { Negative regulation of } \\
\text { transcription from } \\
\text { RNA polymerase II promoter }\end{array}$ & 0.008 & Cell cycle phase transition & $6.100 e-5$ \\
\hline $\begin{array}{l}\text { Secondary } \\
\text { biosynthesis } \\
\text { process }\end{array}$ & $2.300 \mathrm{e}-13$ & $1.924 \mathrm{e}-10$ & $5.771 \mathrm{e}-10$ & Oxidation-reduction process & 0.013 & Oxidation-reduction process & 0.003 \\
\hline $\begin{array}{l}\text { Steroid biosynthesis } \\
\text { process }\end{array}$ & $1.400 \mathrm{e}-12$ & $8.782 \mathrm{e}-10$ & $3.513 e-9$ & Sterol biosynthesis process & 0.039 & $\begin{array}{l}\text { Negative regulation of } \\
\text { transcription from RNA } \\
\text { polymerase II promoter }\end{array}$ & 0.008 \\
\hline $\begin{array}{l}\text { Sterol metabolic } \\
\text { process }\end{array}$ & $1.300 \mathrm{e}-10$ & $6.523 e-8$ & $3.262 \mathrm{e}-7$ & Steroid biosynthesis process & 0.044 & & \\
\hline
\end{tabular}



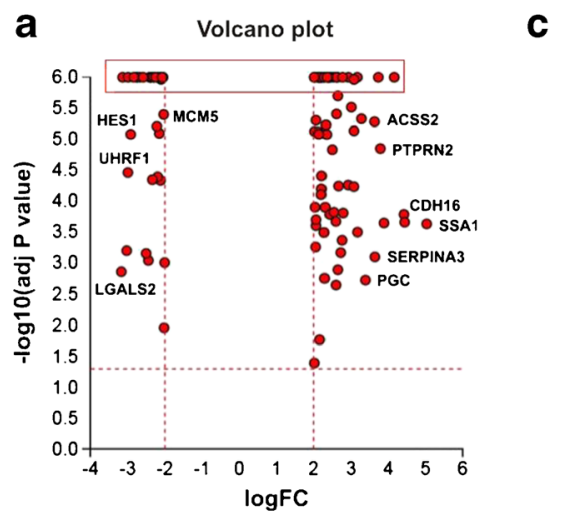

Pathways perturbation vs. over-representation

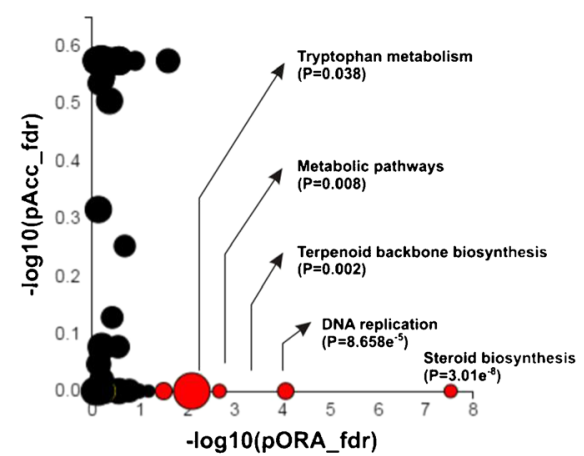

b Top 20 up and down regulated genes

\begin{tabular}{cccccc}
\hline Gene ID & LogFC & P-value & Gene ID & LogFC & P-value \\
\hline \multicolumn{3}{c}{ Up-regulated } & \multicolumn{3}{c}{ Down-regulated } \\
\hline BIRC3 & 2.387 & $1.00 E-06$ & DTL & -2.31 & $1.00 E-06$ \\
BCL6 & 2.126 & $1.00 E-06$ & GINS2 & -2.677 & $1.00 E-06$ \\
CD70 & 2.081 & $1.00 E-06$ & DOC & -2.097 & $1.00 E-06$ \\
CYPS1A1 & 2.627 & $1.00 E-06$ & E2F2 & -2.752 & $1.00 E-06$ \\
DHCR7 & 2.416 & $1.00 E-06$ & FEN1 & -3.138 & $1.00 E-06$ \\
DUSP1 & 2.459 & $1.00 E-06$ & ID3 & -2.388 & $1.00 E-06$ \\
TSC2203 & 3.73 & $1.00 E-06$ & MYBL2 & -2.173 & $1.00 E-06$ \\
EIFAA2 & 2.223 & $1.00 E-06$ & MCM4 & -2.108 & $1.00 E-06$ \\
FDFT1 & 2.127 & $1.00 E-06$ & NPTX1 & -2.991 & $1.00 E-06$ \\
CXCL1 & 2.183 & $1.00 E-06$ & HJURP & -2.078 & $1.00 E-06$ \\
HMGCR & 2.165 & $1.00 E-06$ & MCM10 & -2.838 & $1.00 E-06$ \\
IGF2 & 2.268 & $1.00 E-06$ & RAD51 & -2.412 & $1.00 E-06$ \\
IGFBP1 & 2.607 & $1.00 E-06$ & POLA2 & -2.101 & $1.00 E-06$ \\
IDI1 & 2.291 & $1.00 E-06$ & RRM2 & -2.119 & $1.00 E-06$ \\
INSIG1 & 2.526 & $1.00 E-06$ & C16orf75 & -2.247 & $1.00 E-06$ \\
ISS & 2.923 & $1.00 E-06$ & TFRC & -2.765 & $1.00 E-06$ \\
MVD & 2.415 & $1.00 E-06$ & RIBC2 & -2.368 & $1.00 E-06$ \\
SC4MOL & 3.165 & $1.00 E-06$ & CLDN2 & -2.395 & $1.00 E-06$ \\
SNHG1 & 2.211 & $1.00 E-06$ & EXO1 & -2.051 & $1.00 E-06$ \\
SNHG12 & 2.282 & $1.00 E-06$ & FAM111B & -2.586 & $1.00 E-06$ \\
\hline
\end{tabular}

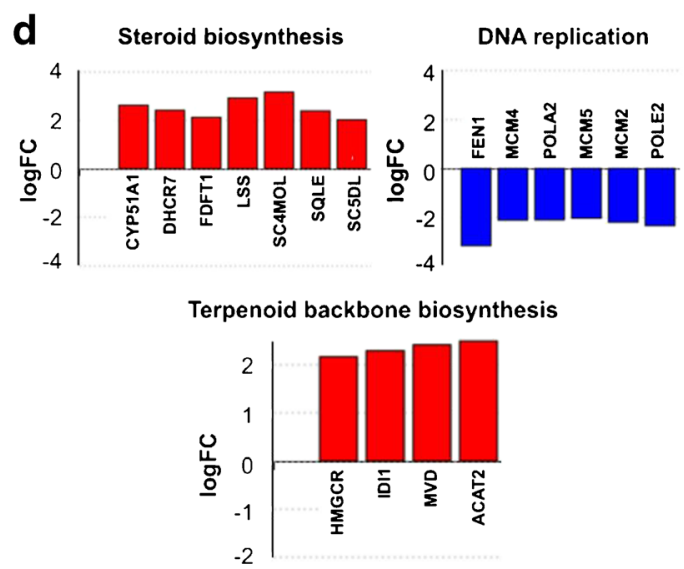

Fig. 3 Whole human genome microarray analysis of A549 cells incubated for $24 \mathrm{~h}$ with simulated lung fluid (SLF) or standard tissue culture media. Panel (a) Volcano plot: All I 16 significantly differentially expressed (DE) genes are displayed according to their measured expression change ( $\mathrm{x}$-axis) and negative log (base 10) of the $p$-value ( $y$-axis). The higher the gene is plotted on the $y$-axis, the more significant it is. The dotted line shows the thresholds for expression change; $p<0.05$. The top 20 up and down regulated genes, reflecting the highlighted section in panel A are provided in panel (b). Panel (c) - Pathways perturbation vs over-representation: The most disrupted pathways are plotted in terms of the two types of evidence: over-representation on the $x$-axis (pORA) and the total perturbation accumulation on the $y$-axis (PAcc). Red spots indicate significantly perturbed pathways, with the size of the spot reflecting the number of DE genes within the identified pathways. Panel (d) illustrates the DE genes within the three most significant pathways identified as perturbed following incubation with the SLF.

than FP and for both drugs the dissolution rate in SLF was greater than in Gamble's solution, but lower than the rate in $0.5 \%$ SDS. An estimate for the solubility of FP in the lungs using mechanistic modelling [43] appears to support the value obtained with SLF, supporting the hypothesis that the salt solution is likely to underestimate the dissolution of hydrophobic drugs, while $0.5 \%$ SDS may overestimate solubility and hence dissolution in the lungs. FP and BDP were selected to represent inhaled drugs that have poor aqueous solubility and may be dissolution limited, accounting for their relatively slow dissolution profiles which appear to contrast with the rapid onset of action that can be observed for some inhaled molecules, e.g. many bronchodilators. However, it is important to appreciate that oral inhaled product dissolution methods are at an early stage of development and are not optimised for in vitro-in vivo correlation. Furthermore, PK-PD relationships to link the potency of inhaled drugs, physicochemical properties, drug formulation, dose interval, temporal profiles of free (unbound) drug concentration at the effect site and pharmacological response are at a nascent stage of development $(43,44)$.

Using more physiological conditions for in vitro investigations into inhalation biopharmaceutics may improve the accuracy of physiologically-based mechanistic modeling and in the future biorelevence may be extended to reflect any differences in RTLF in lung disease and the influence of less abundant components that are recognized to have functional significance, e.g. surfactant proteins that are concentrated in the corona that forms on the surface of biopersistent nanoparticles and influences their uptake $[45,46]$.

\section{CONCLUSIONS}

We report a synthetic simulated lung fluid based on human RTLF that can be used for the in vitro studies 
Fig. 4 (a) Solubility.

Beclomethasone dipropionate

(BDP) and fluticasone propionate

(FP) solubility in media used to represent lung fluid: Gamble's

solution, the biorelevant simulated

lung fluid, SLF, Survanta ${ }^{\circledR}$ and $0.5 \%$

SDS. (b) Dissolution of BDP.

Aerosol from QVAR® $50 \mu \mathrm{g}$

pressurised metered dose inhalers,

(c) Dissolution of FP. Aerosol

from Flixotide ${ }^{\circledR} 50 \mu$ g pressurised

metered dose inhalers. Data

represent mean $\pm \mathrm{sd}, n=3$.
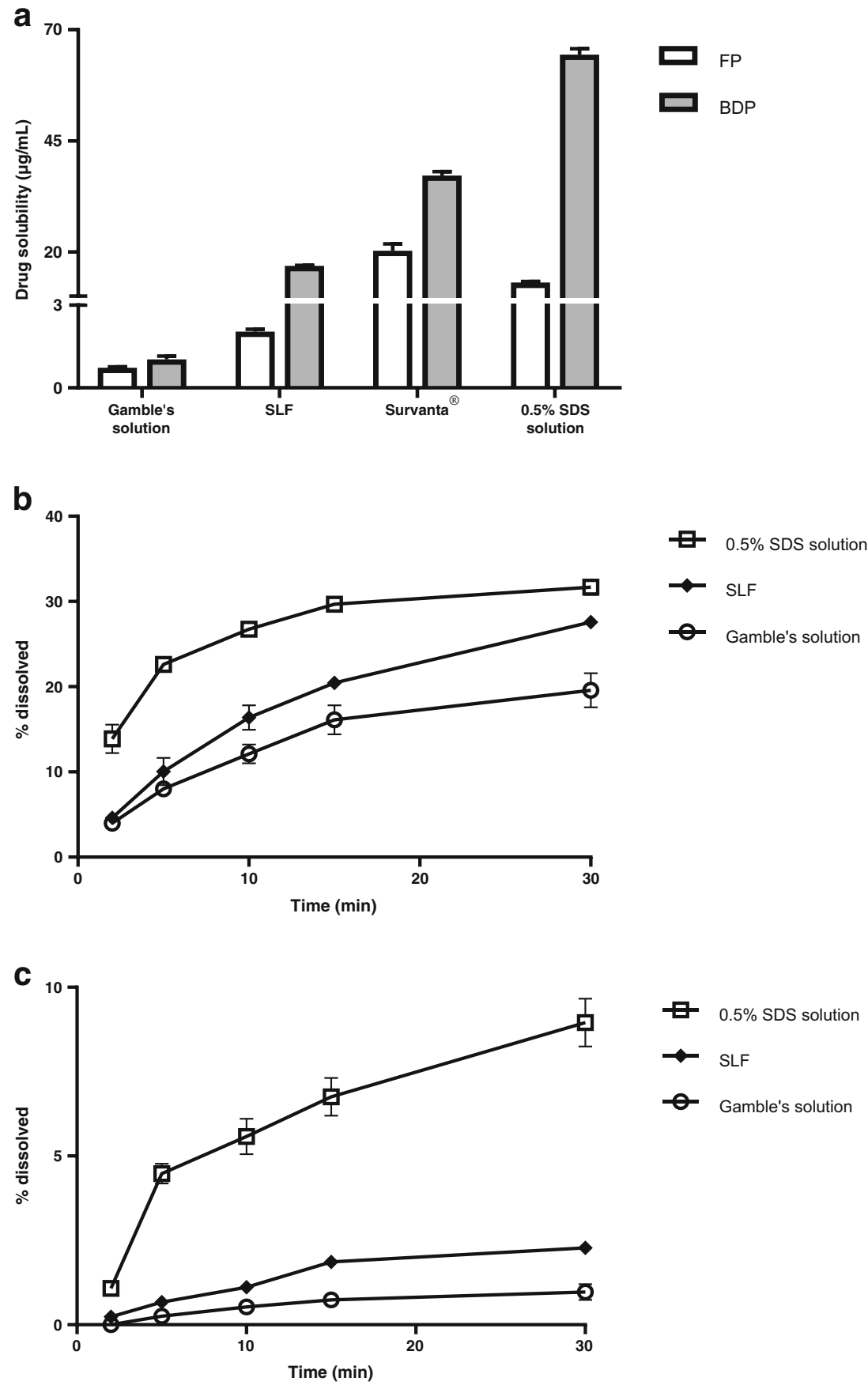

into inhalation biopharmaceutics, e.g. the solubility of inhaled drugs, dissolution of aerosol particles and particle-lung cell interactions. The SLF has a stable colloidal structure, possessing vesicles that are similar in nature to those found in lung extracts. No adverse effects on A549 cells were observed after exposure to the simulant for $24 \mathrm{~h}$, although some metabolic changes were indicated that are consistent with the change of culture medium to a more physiologic composition.
Based on preliminary results, we hypothesize that the use of biorelevant medium provides realistic estimates of the solubility and dissolution of hydrophobic drugs in vivo. Whilst the present SLF was based on the composition of RTLF from the alveolar region of healthy subjects, we acknowledge that further work is still required to develop simulants reflective of different regions of the airway, as well as variation in composition associated with established respiratory disease. 


\section{ACKNOWLEDGEMENTS AND DISCLOSURES}

This research received support from the QualityNano project http://www.qualitynano.eu which is financed by the European Community Research Infrastructures under the FP7 Capacities Programme (Grant No. INFRA-2010262,163), and its partners VITO (for transcriptomics) and Uppsala University (for CryoTEM). Elif Melis Bicer was supported by a BBSRC-CASE studentship (BB/1532696/1) in association with GlaxoSmithKline Research \& Development. Mireille Hassoun was supported by a BBSRC-CASE studentship (BB/K012762/1), in association with Intertek-Melbourn.

Open Access This article is distributed under the terms of the Creative Commons Attribution 4.0 International License (http://creativecommons.org/licenses/by/4.0/), which permits unrestricted use, distribution, and reproduction in any medium, provided you give appropriate credit to the original author(s) and the source, provide a link to the Creative Commons license, and indicate if changes were made.

\section{REFERENCES}

1. Bäckman P, Adelmann H, Petersson G, Jones CB. Advances in inhaled Technologies: understanding the therapeutic challenge, predicting clinical performance, and designing the optimal inhaled product. Clin Pharmacol Ther. 2014;95:509-20.

2. Borghardt JM, Weber B, Staab A, Kloft C. Pharmacometric models for characterizing the pharmacokinetics of orally inhaled drugs. AAPS J. 2015;17:853-70.

3. Edsbacker S, Wollmer P, Selroos O, Borgstrom L, Olsson B, Ingelf $\mathrm{J}$. Do airway clearance mechanisms influence the local and systemic effects of inhaled corticosteroids? Pulm Pharmacol Ther. 2008;21: 247-58.

4. Patton JS, Brain JD, Davies LA, Fiegel J, Gumbleton M, Kim K-J, et al. The particle has landed-characterizing the fate of inhaled pharmaceuticals. J. Aerosol Med. Pulm. Drug Deliv. 2010;23(Suppl 2):S71-87.

5. Foster WM, Langenback E, Bergofsky EH. Measurement of tracheal and bronchial mucus velocities in man : relation to lung clearance. J Appl Physiol. 1980;48:965-71.

6. Stöber WKW. A simple pulmonary retention model accounting for dissolution and macrophage-mediated removal of deposited polydisperse particles. Inhal. Toxicol. 2001;13:129-48.

7. Jones RM, Neef N. Interpretation and prediction of inhaled drug particle accumulation in the lung and its associated toxicity. Xenobiotica. 2012;42:86-93.

8. Forbes B, O'Lone R, Allen PP, Cahn A, Clarke C, Collinge M, et al. Challenges for inhaled drug discovery and development: Induced alveolar macrophage responses. Adv. Drug Deliv. Rev. Elsevier B.V. 2014;71:15-33.

9. Hastedt JE, Bäckman P, Clark AR, Doub W, Hickey A, Hochhaus $\mathrm{G}$, et al. Scope and relevance of a pulmonary biopharmaceutical classification system AAPS/FDA/USP workshop march 16-17th, 2015 in Baltimore. MD AAPS Open AAPS Open. 2016;2:1-20.

10. Lennernäs H, Aarons L, Augustijns P, Beato S, Bolger M, Box K, et al. Oral biopharmaceutics tools - time for a new initiative - an introduction to the IMI project OrBiTo. EurJ Pharm Sci. 2014;57: 292-9.

11. Augustijns P, Wuyts B, Hens B, Annaert P, Butler J, Brouwers J, et al. Eur. J. Pharm. Sci. Elsevier B.V. 2014;57:322-32.

12. Riethorst D, Baatsen P, Remijn C, Mitra A, Tack J, Brouwers J, et al. An in-depth view into human intestinal fluid colloids: intersubject variability in relation to composition. Mol. Pharm. 2016;13: 3484-93.

13. Wuyts B, Riethorst D, Brouwers J, TackJ, Annaert P, Augustijns P. Evaluation of fasted and fed state simulated and human intestinal fluids as solvent system in the Ussing chambers model to explore food effects on intestinal permeability. Int. J. Pharm. Elsevier B.V. 2015;478:736-44.

14. Marques MRC, Loebenberg R, Almukainzi M. Simulated biological fluids with possible application in dissolution testing. Dissolution Technol. 2011;18:15-28.

15. Patel N, Forbes B, Eskola S, Murray J. Use of simulated intestinal fluids with Caco-2 cells and rat ileum. Drug Dev Ind Pharm. 2006:32:151-61.

16. Klein $\mathrm{S}$. The use of biorelevant dissolution media to forecast the in vivo performance of a drug. AAPS J. 2010;12:397-406.

17. Arora D, Shah KA, Halquist MS, Sakagami M. In vitro aqueous fluid-capacity-limited dissolution testing of respirable aerosol drug particles generated from inhaler products. Pharm Res. 2010;27: 786-95.

18. Davies NM, Feddah MR. A novel method for assessing dissolution of aerosol inhaler products. Int J Pharm. 2003;255:175-87.

19. Son YJ, McConville JT. Development of a standardized dissolution test method for inhaled pharmaceutical formulations. Int J Pharm. 2009;382:15-22.

20. May S, Jensen B, Weiler C, Wolkenhauer M, Schneider M, Lehr CM. Dissolution testing of powders for inhalation: influence of particle deposition and modeling of dissolution profiles. Pharm Res. 2014;31:3211-24.

21. Buttini F, Miozzi M, Balducci AG, Royall PG, Brambilla G, Colombo $\mathrm{P}$, et al. Differences in physical chemistry and dissolution rate of solid particle aerosols from solution pressurised inhalers. Int. J. Pharm. Elsevier B.V. 2014;465:42-51.

22. Rohrschneider M, Bhagwat S, Krampe R, Michler V, Breitkreutz J, Hochhaus G. Evaluation of the Transwell system for characterization of dissolution behavior of inhalation drugs: effects of membrane and surfactant. Mol Pharm. 2015;12:2618-24.

23. Pham S, Wiedmann TS. Dissolution of aerosol particles of budesonide in Survanta, a model lung surfactant. J Pharm Sci. 2001;90:98-104.

24. Bicer EM. Compositional characterisation of human respiratory tract lining fluids for the design of disease specific simulants. King's College London 2015.

25. Kumar A, Bicer EM, Morgan AB, Pfeffer PE, Monopoli M, Dawson KA, et al. Enrichment of immunoregulatory proteins in the biomolecular corona of nanoparticles within human respiratory tract lining fluid. Nanomed Nanotechnol Biol. Med. Elsevier B.V. 2016;12:1033-43.

26. Scarpelli EM, Gabbay KH, Kochen JA. Lung surfactants, Counterions, and hysteresis. Science. 1965;148:1607-9.

27. Vollhardt D, Fainerman VB. Progress in characterization of Langmuir monolayers by consideration of compressibility. Adv Colloid Interf Sci. 2006;127:83-97.

28. Choi Y, Attwood SJ, Hoopes MI, Drolle E, Karttunen M, Leonenko Z. Melatonin directly interacts with cholesterol and alleviates cholesterol effects in dipalmitoylphosphatidylcholine monolayers. Soft Matter. 2014;10:206-13.

29. Dynarowicz-Łatka P, Hac-Wydro K. Interactions between phosphatidylcholines and cholesterol in monolayers at the air/water interface. Colloids Surfaces B Biointerfaces. 2004;37:21-5. 
30. Grainger CI, Saunders M, Buttini F, Telford R, Merolla LL, Martin GP, et al. Critical characteristics for corticosteroid solution metered dose inhaler bioequivalence. Mol Pharm. 2012;9:563-9.

31. Filipe V, Hawe A, Jiskoot W. Critical evaluation of nanoparticle tracking analysis (NTA) by NanoSight for the measurement of nanoparticles and protein aggregates. Pharm Res. 2010;27:796-810.

32. Lee KYC, Gopal A, von Nahmen A, Zasadzinski JA, Majewski J, Smith GS, et al. Influence of palmitic acid and hexadecanol on the phase transition temperature and molecular packing of dipalmitoylphosphatidyl-choline monolayers at the air-water interface. J Chem Phys. 2002;1 16:774.

33. Pérez-Gil J, Keough KMW. Interfacial properties of surfactant proteins. Biochim. Biophys. Acta - Mol. Basis Dis. 1998;1408: 203-17.

34. Antal JM, Divis LT, Erzurum SC, Wiedemann HP, Thomassen MJ. Surfactant suppresses NF-KB activation in human Monocytic cells. Am J Respir Cell Mol Biol. 1996;14:374-9.

35. Morris RHK, Tonks AJ, Jones KP, Ahluwalia MK, Thomas AW, Tonks A, et al. DPPC regulates COX-2 expression in monocytes via phosphorylation of CREB. Biochem Biophys Res Commun. 2008;370:174-8.

36. Tokumura T, Miyazaki E, Isaka H, Kaneko N, Kanou M. Solubility of fluticasone propionate in aqueous solutions measured by a method avoiding its adsorption to experimental tools. Int Res J Pharm Appl Sci. 2014;4:19-24.

37. Sahib MN, Abdalwahed S, Abdulameer DY, Peh KK, YTF T. Solubilization of beclomethasone dipropionate in sterically stabilized phospholipid nanomicelles (SSMs): Physicochemical and in vitro evaluations. Drug Des. Devel. Ther. 2012;6:29-42.

38. Wiedmann TS, Bhatia R, Wattenberg LW. Drug solubilization in lung surfactant. J Control Release. 2000;65:43-7.
39. Liao X, Wiedmann TS. Solubilization of cationic drugs in lung surfactant. Pharm Res. 2003;20:1858-63.

40. Kim K, Choi SQ, Zell ZA, Squires TM, Zasadzinski JA. Effect of cholesterol nanodomains on monolayer morphology and dynamics. Proc Natl Acad Sci U S A. 2013;110:E3054-60.

41. Kim SH. Adsorption and interactions of lung surfactant lipids and proteins at air/aqueous interfaces and in aqueous solution. Purdue University; 2007.

42. Das SC, Stewart PJ. The influence of lung surfactant liquid crystalline nanostructures on respiratory drug delivery. Int J Pharm. 2016;514:465-74.

43. Boger E, Evans N, Chappell M, Lundqvist A, Ewing P, Wigenborg A, et al. Systems pharmacology approach for prediction of pulmonary and systemic pharmacokinetics and receptor occupancy of inhaled drugs. CPT Pharmacometrics Syst Pharmacol. 2016;5:201-10.

44. Cooper AE, Ferguson D, Grime K. Optimisation of DMPK by the inhaled route: challenges and approaches. Curr Drug Metab. 2012;13:457-73.

45. Shaw CA, Mortimer GM, Deng ZJ, Carter ES, Connell SP, Miller MR, Duffin R, Newby DE, Hadoke PWF, Minchin RF. Protein corona formation in bronchoalveolar fluidenhances diesel exhaust nanoparticle uptake and proinflammatory responses in macrophages. Nanotoxicology. 2016;10:981-91.

46. Wohlleben W, Driessen MD, Raesch S, Schaefer UF, Schulze C, von Vacano B, Vennemann A, Wiemann M, Ruge CA, Platsch $\mathrm{H}$, Mues S, Ossig R, Tomm JM, Schnekenburger J, Kuhlbusch TAJ, Luch A, Lehr C-M, Haase A. Influence of agglomeration and specific lung lining lipid/protein interaction on short-term inhalation toxicity. Nanotoxicology. 2016;10:970-80. 